\title{
Extending Holonic Manufacturing Systems To Achieve The Virtual Supply Chain Domain
}

\author{
Marcos Ricardo Rosa Georges \\ PUC-Campinas \\ marcos.georges@puc-campinas.edu.br \\ Gustavo Nucci Franco \\ Arbeit Engenharia \\ nfranco@uol.com.br
}

\author{
Antonio Batocchio \\ Universidade Estadual de Campinas \\ batocchi@fem.unicamp.br
}

\begin{abstract}
Increased competition in the global market place has forced companies to seek better products and services, with lower cost and in a market suitable time. According to the holonic manufacturing paradigm, those requirements could be achieved if a reconfigurable enterprise were developed from autonomous and intelligent agents that dynamically interact with each other. This system should be able to automatically organize itself in such a way that its functions were arranged to achieve the finest performance. But if this system was really effective and proactive, it should search for functionalities beyond its own boundaries; it could obtain better competitive edges if it were gathering external partners that do some tasks in better ways than it ordinarily does by itself. Hence, the virtual supply chain, in its sense of distributed enterprises aggregation, can be a natural result of holonic manufacturing systems. This paper illustrates the advantages of using holonic concepts in the virtual supply chain realm through the self-organization of dynamic systems, exploring the holonic paradigm as a catalyst to enable this aggregation. Hence holonic manufacturing models will be seen as important references to virtual supply chains.
\end{abstract}

Keywords: Virtual Supply Chain; Intelligent Manufacturing Systems; Holonic Manufacturing Systems; Supply Chain Management; Virtual Enterprises

\section{INTRODUCTION}

As a modern approach to gather market opportunities into a distributed system, virtual enterprises and supply chain management have faced many developmental common problems. For instance, a substantial effort has been dispended to go beyond the heterogeneity of enterprises legacy systems. Further, the attempt to solve distributed coordination problems between various self-assertive entities has been a faced challenge.

These kinds of problems could hark back to General Systems Theory concepts [von Bertalanffy, 1976]. Doing so, any kind of organization could be analyzed at once and mutually dependent variables could be found. Once a problem could be described in other environment and a clearer solution be developed, this image could be transposed to the desired domain.
This paper's objective is to show that the concept of holonic management system could help managers to understand the problems of structure, coordination and discipline of their supply chains. Like the elements of these chains, holons - as will be defined in part 4 - must obey to systemic goals, but should also be agile and flexible independent decision makers, in order to respond in an intelligent way to changes in market demand.

According to the holonic manufacturing paradigm, those requirements could be achieved if a reconfigurable enterprise were developed from autonomous and intelligent agents that dynamically interact with each other. This system should be able to automatically organize itself in such a way that its functions were arranged to achieve the finest performance. An example of such an approach is the study of the ho- 
lonic manufacturing that uses sociological, economical and even biological metaphors to develop more agile and intelligent manufacturing systems. At the Katholiek Universiteit Lueven, this paradigm was used to propose a HMS (Holonic Manufacturing System) reference model [Van Brussel et al., 1997]. Franco \& Batocchio (2000) brought such an artifice into play to discuss the coordination problem of virtual enterprises.

But if this system were really effective and proactive, it should search for functionalities beyond its own boundaries; it could obtain better competitive edges if it were gathering external partners that do some tasks in better ways than it ordinarily does by itself. Hence, the virtual supply chain, in its sense of distributed virtual enterprises aggregation, can be a natural result of holonic manufacturing systems.

In this work, the concepts of the holonic manufacturing are extended to enable a new virtual clustering approach. It uses some concepts of self-organization of dynamic systems, exploring the holonic paradigm as a catalyst to enable this aggregation, supporting the collaboration and coordination between virtual enterprises that compose the virtual supply chain. Hence, the holonic manufacturing models will be seen as important references to virtual supply chain.

\section{VIRTUAL ENTERPRISE AND SUPPLY CHAIN KEY ASPECTS}

The evolution of new technologies is enabling a more effective sharing and exchanging of information across individuals and organizations. The concept of virtual enterprise challenges the way industrial production systems are planned and managed [Camarinha-Matos et al., 1997].

According to the National Industrial Information Infrastructure Protocols (NIIIP) Consortium, a "virtual enterprise is a temporary consortium or alliance of companies formed to share costs and skills and exploit fast-changing market opportunities" [NIIIP Consortium, 1998]. Walton \& Whicker (1996) say that the "virtual enterprise consists of a series of co-operating nodes of core competence which form into a supply chain in order to address a specific opportunity in the marketplace". Ouzonis et al. (1998) define a virtual enterprise as "a set of legally independent performers of varying types who voluntarily co-operate to seize a market opportunity".

In fact, many researches have focused on this outstanding paradigm, but even if many have an understanding, no common definition exists and a number of competing different terms are either referee to the same concept or to its different perspectives. Among them, extended enterprises, supply chains networks and virtual corporations are commonly used terms that, although not necessarily synonymous, represent the same concept: a temporary alliance of enterprises that come together to share skills and resources in order to better respond to business opportunities [Camarinha-Matos, 1997].

But a virtual enterprise is not just a collection of partners. As seen in figure 1 [Spinosa et al., 1998], it should be interpreted as a collaborative structure that must avoid the drawbacks of its madeup lack of boundaries and gather the paybacks of its aggregation of core functions. It is a fact that a set of enterprises can be called social, whereas any enterprise acting alone in the market is solitary. Even though, not all aggregations can be social; it is not enough for a group of enterprises to have the same objectives to be social, but its aggregation is a prelude for further collaboration [Franco \& Batocchio, 2000].

The coordination problem of a virtual enterprise is a special issue, since it is a collection of parts-enterprises that belong to the system, that behave as of self assertive units. Each selected enterprise has to attend to the system's goal, but it also has its own culture, organization and politics.

Once the definition of virtual enterprise as a network of enterprises has been understood, an issue grows up in mind: which kind of aggregation gets the best global performance? In fact, this searching for an optimal organization has been a pervasive issue throughout the organization theory history [von Bertalanffy, 1976; Koffka, 1925]. As it will be seen further in this paper, the holonic manufacturing can be used as a path to the answer of such a question.

\section{Figure 1 - A virtual enterprise representation [Spinosa et al., 1998]}




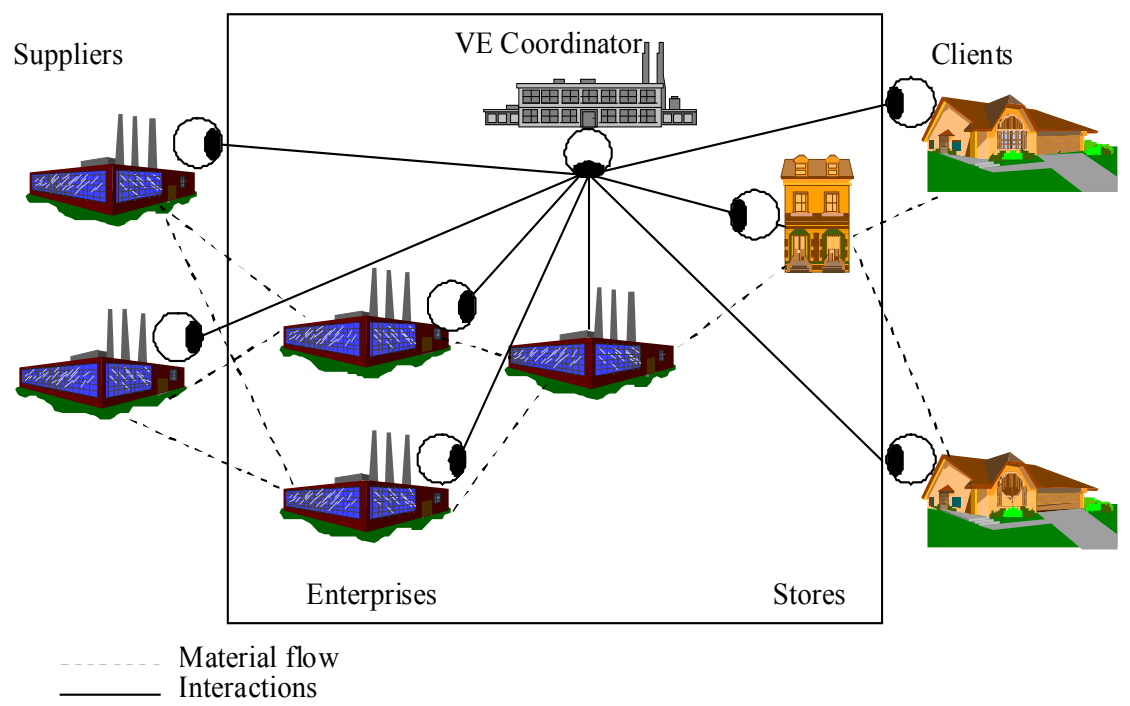

The Council of Supply Chains Management Professionals (CSCMP) defines SCM: "Supply chain management (SCM) encompasses the planning and management of all activities involved in sourcing and procurement, conversion, and all logistics management activities. Importantly, it also includes coordination and collaboration with channel partners, which can be suppliers, intermediaries, third party service providers, and customers. In essence, supply chain management integrates supply and demand management within and across companies".

The typical way of building an SCM system to deal with the complex activities in the supply chain is to integrate several models, e.g. sub-systems such as ERP (enterprise resources planning), ASP (active server pages), PDM (product data management) etc., into a single system. The problem is that most of the sub-systems mentioned above are proprietary and their vendors provide interfaces to other types of subsystems (e.g., PDM to ERP), but seldom to another sub-system of the same type from a different vendor (e.g. ERP to ERP), which makes these components dependent on each other. This could make it difficult to combine different supply chain and enterprise systems due to lack of compatibility among them.

All the traditional SCM systems are extremely complex by nature and it is quite difficult to optimize them as a whole, but using holonic manufacturing systems concepts can change the way the entire system is understood and optimized.

According to Ulieru and Cobzaru (2005) the next generation of SCM systems will have to deal with the supply chain's growing complexity and should possess the following set of characteristics:

- Integration: This is the keyword that appears throughout the new generation of supply chain because it makes the difference between the old view of logistics as the discrete functions of transportation and distribution, and the new vision of SCM that links all the participants and activities involved in converting raw materials into products and delivering them to consumers at the right time and at the right place.

- Customer-centric service: Providing online commitments for orders and schedules is a key factor to enhancing customer service and gaining a competitive advantage. Many companies envision this capability as part of the future SCM strategy. The next generation of SCM would solve customers' problems by:

»Gathering and analyzing knowledge and data about customers' needs.

»Identifying partners to perform the functions needed in the demand chain.

» Moving the functions that need to be done to the chain member that can perform them most effectively and efficiently.

»Developing and executing the best logistics, transportation, and distribution methods to deliver products and services to consumers in a timely manner.

- Synchronization: Next generation of supply chain suites will have to synchronize supplier planning, production planning, logistics planning, and de- 
mand planning. These solutions will provide a comprehensive view of all supply chain activities and enable management to make more informed tradeoff decisions. Supply chain synchronization is the secret to improving customer service without increasing inventory investment.

- Agility: SCM systems must be able to process transactions rapidly and accurately. In today's business environment organizations must focus on moving information and products quickly through the entire supply chain, distribution, assembly manufacture and supply. The faster do parts, information, and decisions flow through an organization, the quicker it can respond to customer needs and orders.

- Flexibility: Next generation of SCM system can create an advantage by being flexible enough to customize its services to meet the needs of distinct customer segments or individual accounts. The flexibility to meet diverse customer needs in a cost-effective way can distinguish a company and allow it to serve a wider customer category.

- Information Protection: In today's global economy it is essential to ensure that information is securely protected while various companies (some of which may be competitors) collaborate within the same supply chain.

\section{INTELLIGENT MANUFACTURING SYSTEMS}

Recently, many efforts has been made to develop advanced manufacturing systems that provide rapid response and dynamic reconfigurable structures to facilitate flexible and efficient use of manufacturing resources in rapidly changing environments [Shen \& Norrie, 1999; Parunak et al., 1997]. Using computational intelligence features such systems are known as intelligent manufacturing systems (IMS). However, when we try to understand the concepts of an IMS, as well as we decide to apply its architectures, techniques, and methodologies, we should reason about a more capital issue: what is intelligence?

Although it is possible to clearly recognize an intelligent behavior, an ultimate definition of intelligence is a challenge to cognitive science researches. As a specific aspect of such a problem, the development of intelligent machines that capture the vitality and the complexity of human mind is a wish to our society and it can be found since the Greek mythology.

The study and comprehension of the human intelligence has led to many scientific developments.
From the idea that the logic is the basis of the whole Mathematics, according to Bertrand Russell and Albert N. Whitehead, and passing through John von Neumann's basic computer architecture and Norbert Wiener's "Cybernetics", the late 20th century has witnessed a special collection of works that steered to the current computational systems. In 1950, Alan M. Turing encouraged many works with his "Turing Test". That was the replacement of the intelligence definition issue by an empiric test. In one of his essays, Turing wrote: "I believe that at the end of the century the use of words and general educated opinion will have altered so much that one will be able to speak of machines thinking without expecting to be contradicted".

Nevertheless we are on the 21st century and, even with exponential technological improvements, no machine succeeds in the attempt to accomplish consistently the Turing Test. Computers could win human chess champions over extraordinary matches, but they could not solve a simple problem like the construction of a castle with child blocks unless directly programmed. According to Marvin Minsky, the major challenge is to give common sense to machines. That is what is needed for the chess machine to perceive by itself that the same problem solving algorithm could be used to elucidate both problems.

Returning to our realm, it is possible to see that such concepts can be also applied to systems other than machines. Hence, new manufacturing systems have been developed, offering new capabilities that allow the response to pressures like distribution, agility and customization. Those systems are support to decision-making process and they could be represented by higher level knowledge based systems or upper level automated systems.

\section{THE HOLONIC PARADIGM}

The holonic paradigm is based on the work done by the Hungarian journalist Arthur Koestler in the late 60's. His book "The Ghost in the Machine" discusses the nature of complex systems, such as the human brain, living beings and societies [Koestler, 1967]. Refuting the behaviorist school, which was the dominant regulator of the experimental psychology at that time, Koestler unveiled some new view of the reasons that allows any evolution process.

Koestler mostly strives in the structural and behavioral aspects of complex systems. He asserted that any organization with some degree of coher- 
ence and stability was hierarchically ordered. The Economy Nobel Prize Herbert Simon had already illustrated this principle in his watchmaker parable [Simon, 1962], noting that hierarchies will evolve much more rapidly from elementary constituents that will non-hierarchic systems with the same number of elements. The General System Theory demonstrated the importance of hierarchic structures to fulfill the whole existence on Earth [von Bertanffy, 1976]: "a complex system can be faster enhanced from simple structures if there are stable intermediate forms".

Koestler's second conclusion was that, although parts and wholes are easily identified in complex systems, parts and wholes in their absolute sense do not exist anywhere. Koestler proposed the word holon (connection of holos, whole in Greek, with the suffix on, that indicates part or particle as in proton and neutron), describing the hybrid nature of these components. In holons, the wholes are assertive holistic elements in relation to their subordinated parts, at the same time that they are atomic parts dependent on higher levels.

Koestler also created the word holarchy to refer to a hierarchical organization of holons, as the one seen in figure 2. Holarchies are open-ended at the top and at the bottom. The top-level holon, being the overall whole, can still contain smaller components inside. Each holon can also belong to as many holarchies as necessary.

\section{Figure 2 - A holonic structure or holarchy [Bell et al., 1998]}

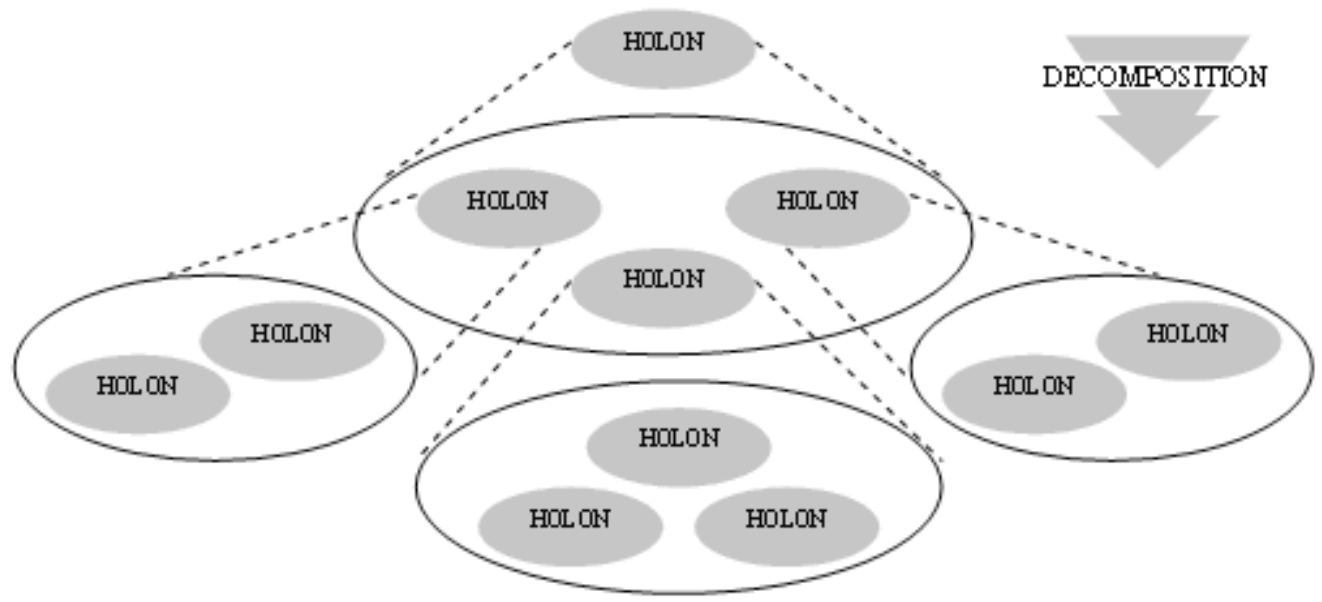

The holonic manufacturing, which refers to the application of Koestler's concepts of holon in the design and development of future manufacturing systems, was firstly been highlighted by Suda [Suda, 1989]. The main goal is to reach an intelligent manufacturing system that deals to continuous market changes that require expressive changes in the production system; i.e. systems that can adapt to the new situation easier than a competing system, gaining benefit from this:

- Adapting faster than the competition gives a higher benefit in using new opportunities,

- Having a lower cost/effort for adaptation allows profiting from smaller, temporal opportunities.

The holonic manufacturing paradigm offers a new approach to computer integrated manufacturing
(CIM). The occurrence of changes and disturbances are considered as normal system occurrences, and the manufacturing control system shall be able to effectively handle these situations. Therefore, the holonic manufacturing system is capable to attend to a larger scale of opportunities, once its intelligent behavior makes it skilled enough to identify in its local capabilities a distributed configuration that attends to a specific requirement.

But the fundamental holonic concepts are not restricted to highly automated systems. Koestler's studies on a range of social and biological organizations show that the holonic paradigm can be as well applicable to human centered systems [Toh, 1997]. At the present time, many researchers have focused on the study of small to medium enterprises, the 
ones that occupy a position at the end of the supply chain of large important companies, developing technologies to make them more agile.

Holonic manufacturing systems [Christensen, 1994] have been explored in the past ten years as a new step towards distributed intelligent architectures for manufacturing [Ulieru, et al 2002]. They were also thought as an alternative solution to traditional architectures (e.g. Computer Integrated Manufacturing Systems) that have a low capacity to adapt and react to dynamic changes in the environment such as disturbances and market changes [Ulieru, et al 2002]. A holonic manufacturing system is composed of functional manufacturing units called holons units that display the dual properties of autonomy and cooperativeness. A holon as defined by the Holonic Manufacturing Systems (HMS) [Christensen, 1994] consists of an information processing part and often a physical processing part and can be part of another holon in a nested hierarchy. The activities of each holon are determined through cooperation with other holons, as opposed to being determined by a centralized mechanism.

The Holonic Enterprise can be viewed as an information ecosystem composed of collaborative but autonomous holons, like the figure 3 shows.

Figure 3 - Layers in Holonic Manufacturing defining a Manufacturing Holarchy (Ulieru and Cobzaru, 2005)

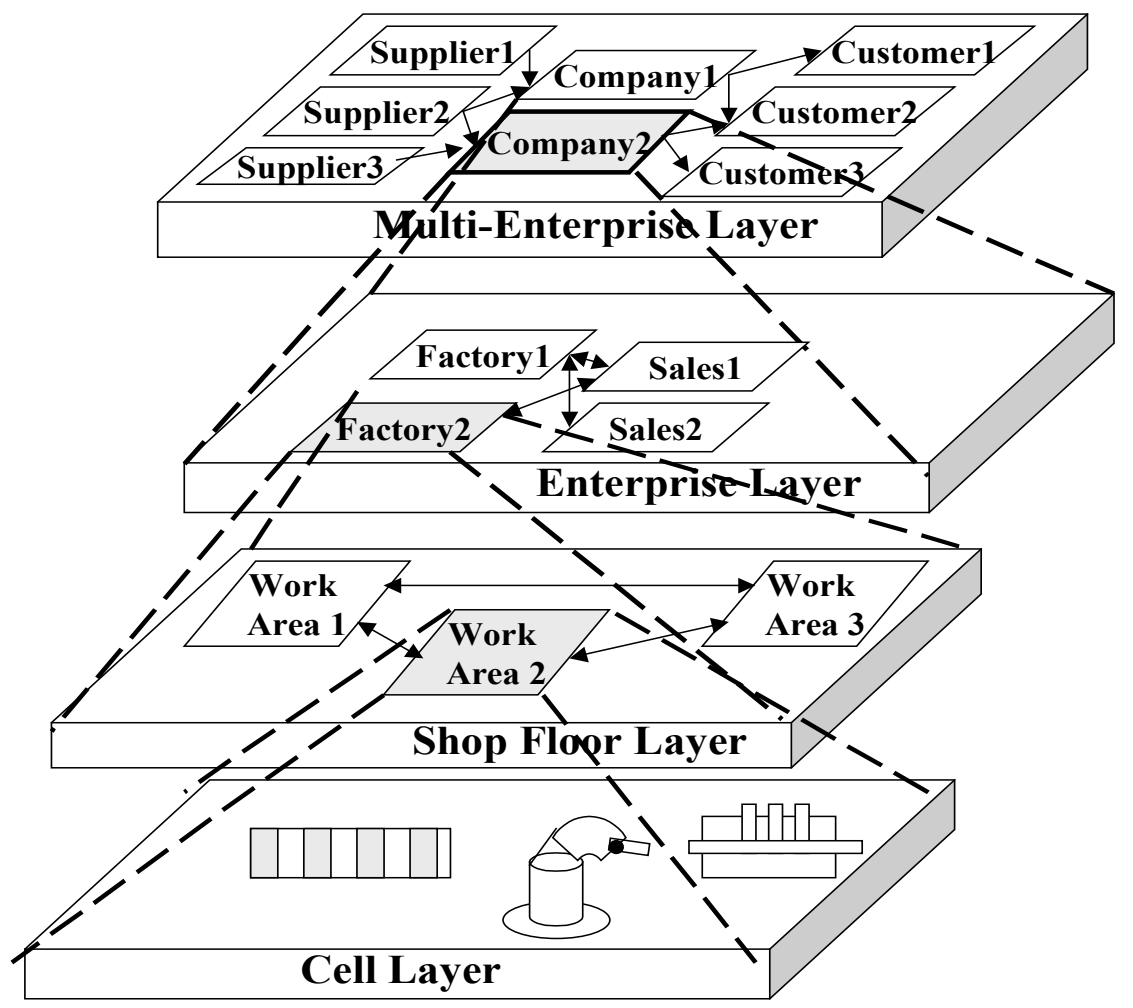

Some examples of holons are found in the automotive supply chain, in which successive tiers of suppliers, starting at the nuts and bolts level, assemble parts into subsystems up to the final product; in the supermarket supply chain, in which hundreds of manufacturers and third part logistics providers cooperate to deliver the some 50.000 different items available on the shelves; in research networks, made of teams of scientists working together to develop new products; and in the web itself. And manufacturing displays, already for many years, numerous examples of artificial intelligence and holonic cooperation, like medical diagnostic sys- tems, entirely automatic self-controlling factories (paper, chemicals), computer integrated manufacturing (CIM), automatic stock and retrieval systems (AS-RS), flight simulators and many other instances.

\section{THE SELF-ORGANIZATION VIEWPOINT}

In a previous section of this paper, we depicted our concern about the kind of organization that better represents an organized system. With such a answer, it would be easier to achieve virtual enterprises with a better chance of success. In fact, this problem is far 
from a solution. But our purpose in this paper is to show the benefits of using the holonic paradigm in cluster of enterprises virtually organized.

Michel Debrun says that an organization or "frame" is self-organized when it is produced by itself [Debrun, 1996]. The process of self-organization can be viewed as the evolution of organized systems with complexity variation (increasing or diminishing), be it structural or functional.

But, is it possible to depict precisely our intuition about an organized, ordered and complex system? Osvaldo Pessoa Jr. cites fifteen definitions that can be found in the literature for such systemic measures. One of them, perhaps the clearest one, is the complexity as number of elements. Thus, the complexity of a system can be defined as the number of elements that compose it. In this sense, a holonic system can be called organized, once some of its attributes, like modularity and recursivity, reduce the number of "species" into this system.
Other definition is the organization as conditionality, in the sense that it is related to the number of connections between elements. Such an organization definition involves the structural as well as functional organization. Consequently, one complex system with an elaborated net of connections is not necessarily efficient. That is the point in which the autonomy of elements can be crucial, once it reduces the interactions between the system's elements.

There is also a definition related to the organization as grouping that is concerned to the way in which the elements of a set can aggregate themselves into subsets. If the relationship between the elements of the subsets is larger than the relationship between the subsets for all levels, the system is said to be modular [Simon, 1962]. According to that principle, it is possible to create the simple instance shown in figure 4 [Pessoa Jr., 1996]. It can be seen, as well as mathematically proved [Toulouse \& Bok, 1978], that the three leveled cluster is the most organized one and, hence, the one with the maximum efficiency.

Figure 4 - Example of organization as grouping [Pessoa Jr, 1996]

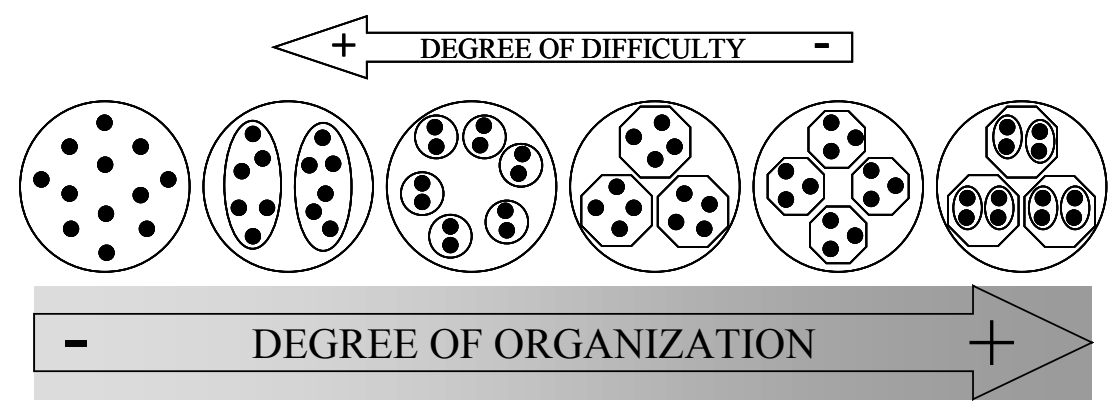

\section{CONCLUSIONS}

In this paper, it was possible to apply the main holonic concepts to the supply chain domain. It can be set out from Koestler (1967) discovery that, in its structural and functional aspects, any organism is a hierarchy of auto-regulated holons that:

- Works as autonomous wholes in supra-ordination of its parts;

- Works as dependent parts in subordination of upper control levels;

- Works in coordination with its local environment (other holons and external environment).
It is important to reinforce the concept of hierarchy that was used. It is not related to the common relationship of boss and employee that is also synonymous of rigidity. In the holonic context, a hierarchy is an opened system of interrelated and recursively hierarchic subsystems, decomposed in a process that does not stop until an elementary (but never final) subsystem is reached.

In the last few years, some works have been done towards the development of new manufacturing systems based on holonic concepts. The holonic paradigm is useful since it discovers innovative questions about the needs of an organism, whether it is a colony of animals or an enterprise. In this sense, 
an effective virtual enterprise environment can be implemented using metaphors such as this.

According to the self-organizing system concept, there are definite advantages in this approach. Using some systemic measurements, it is possible to show the organization and complexity of systems, and the way the holonic concepts achieve clear improvements on them.

To conclude, this paper contribution to the systems theory is to show that the elements of a supply chain should behave as holons, it is, be organized and form a disciplined system, but should also be active and autonomous, adapting themselves efficiently to the many changes nowadays occuring in the global markets.

\section{ACKNOWLEDGEMENTS}

This work could not have been done without the support of the Fundação de Amparo à Pesquisa do Estado de São Paulo (Fapesp), which has provided financial subsidies. It is also important to mention that Recope/Finep/BID has sponsored the infrastructure made available to this research.

\section{REFERENCES}

Ashby, W.R. Principles of the Self-Organizing Dynamic System. In Principles of Self-Organization. Edited by H. von Foerster, G.W. Zopf Jr., p.255-278. Oxford Pergamon, 1962.

Bell, R., Rahimifard, S., Toh, K.T.K. Holonic Systems. In Handbook of Life Cycle Engineering: concepts, models and technologies. Edited by A. Molina, A. Kusiak, J. Sanchez. p.115149. Dondrecht (The Netherlands): Kluwer Academic Press, 1998.

von Bertalanffy, L. General System Theory: foundations, development, applications. Revised Edition, 289pp. New York (NY): George Baziller, 1976

van Brussel, H., Wyns, J., Valckenaers, P., Bongaerts, L., Peeters, P. Reference Architecture for Holonic Manufacturing Systems: PROSA. Computer in Industry, special issue on intelligent manufacturing systems, 1997.

Christensen JH. “Holonic manufacturing systems: initial architecture and standards directions". In Proceedings of First European Conference on Holonic Manufacturing Systems, 1994.

Debrun, M. A Idéia de Auto-organização. In Auto-organização: estudos interdisciplinares. Edited by M. Debrun, M.E.Q.
Gonzales, O. Pessoa Jr. Centro de Lógica, Epistemologia e História da Ciência (CLE) - UNICAMP, p.3-23, 1996. (in Portuguese)

Franco, G.N., Batocchio, A. The Holonic Paradigm as a New Metaphor for the Coordination Problem of Virtual Enterprises. 2nd IFIP / MASSYVE Working Conference on Infrastructure for Virtual Enterprises. Edited by: L.M. Camarinha-Matos, H. Afsarmanesh, R.J. Rabelo, Florianopolis (SC), Brazil, Dec. 4-6, 2000, Kluwer Academic Publishers, 2000.

Koestler, A. The Ghost in the Machine. London (UK): Arkana Books, 1967.

Minsky, M. Society of Minds. Heinemann, 1985.

Parunak, H.V.D., Baker, A.D., Clark, S.J. The AARIA Agent Architecture: an example of requirements-driven agent-based system design. In Proceedings of the First International Conference on Autonomous Agents. 1997.

Pessoa Jr., O. Medidas Sistêmicas e Organização. In Auto-organização: estudos interdisciplinares. Edited by M. Debrun, M.E.Q. Gonzales, O. Pessoa Jr. Centro de Lógica, Epistemologia e História da Ciência (CLE) - UNICAMP, p.-129-161, 1996. (in Portuguese)

Shen, W., Norrie, D.H. Agent-Based Systems for Intelligent Manufacturing: a state-of-the-art survey. International Journal of Knowledge and Information Systems. v.1, n.2, p.129-156, 1999.

Simon, H.A. The architecture of complexity. In Proceeding of the American Philosophical. Society, v.106, n.6, p.467-482, 1962.

Spinosa, L.M., Rabelo, R.J., Klen, A.P., Ferreira, A.C. In Proceeding of the Prolamat 98 - Tenth International IFIP TC5 WG-5.2 WG-5.3 Conference, September, 1998, Trento, Italy, 1998.

Suda, H. Future Factory System Formulated in Japan. Japanese Journal of Advanced Automation Technology. v.1, n.1, p.1525,1989 .

Toh, K.T.K. A Reference Model for Information Specification for Metalworking SMEs. Ph.D. Thesis, Loughborough University, UK, 1997.

Toulouse, G., Bok, J. Principe de Moindre Difficulté et Structures Hiérarchiques. Revue Française de Sociologie. n.19, p.391306, 1978. (in French)

Wiener, N. Cybernetics or Control and Communication in the Animal and the Machine. 2ed., 212pp. New Cambridge (MA): MIT Press, 1972.

Ulieru, M. and Mircea Cobzaru. Building Holonic Supply Chain Management Systems: An e-Logistics Application for the Telephone Manufacturing Industry. In IEEE Transactions on Industrial Informatics, Vol1, No. 1, Feb. 2005, pp. 18-31.

Ulieru, M. Brennan R. and Walker, S. "The Holonic Enterprise - A Model for Internet-Enabled Global Supply Chain and Workflow Management", International Journal of Integrated Manufacturing Systems, No 13/8, 2002, ISSN 0957-6061. 


\section{AUTHOR'S BIOGRAPHY}

Marcos Ricardo Rosa Georges has graduation at Matemática Aplicada e Computacional by Universidade Estadual de Campinas (1998), graduation (incomplete) at Estatística by Universidade Estadual de Campinas (2005), master's at Engenharia Mecânica by Universidade Estadual de Campinas (2001) and Ph.D. at Engenharia Mecânica by Universidade Estadual de Campinas (2004). Currently is professor and research at Pontifícia Universidade Católica de Campinas.

Gustavo Nucci Franco has degree in Mechanical Engineering from Universidade Estadual de Campinas (1996), Master in Mechanical Engineering from Universidade Estadual de Campinas (1998) and Ph.D. in Mechanical Engineering from Universidade Estadual de Campinas (2003). He is currently Director of Engineering Franco Arbeit.

Antonio Batocchio has graduation at Engenharia Mecanica by Universidade de São Paulo (1979) , master's at Engenharia Mecânica by Universidade de São Paulo (1987) , Ph.D. at Engenharia Mecânica by Universidade Estadual de Campinas (1991) and Postdoctorate by University of Minnesota (1996). Currently is professor at Universidade Estadual de Campinas. 